\title{
Analisis Tingkat Kapabilitas Knowledge Management System Information Menggunakan Model Framework Cobit 5
}

\section{(Studi Kasus Hotel XYZ)}

\author{
Muhamad Dody Firmansyah ${ }^{[1]^{*}}$ \\ Universitas Internasional Batam, Sistem Informasi Departemen \\ Batam, Indonesia \\ dodyfirmansyah.dodi@gmail.com
}

\begin{abstract}
Knowledge Management System (KMS) to improve the quality of human resources in an organization by improving communication among employees and to increase skill by transferring knowledge. Knowledge Management System (KMS) is one of many ways to foster a culture of knowledge sharing among individuals and organizations. In this research, the researcher tries to develop a model of knowledge management system suitable for existing condition at the Hotel XYZ run effectively, it is necessary to conduct an evaluation activity by examining the process of managing knowledge possessed by each individual can be transferred to other individuals through the process of knowledge sharing and knowledge presentation management and through Effective management of knowledge is expected to be maintained well so that it can provide benefits to the company. KMS (Knowledge Management System) is main tool for implementation of existing processes in the knowledge management, is necessary to do an analysis to find out the extent of the processes of knowledge level management found in Hotel XYZ at the maturity level of KMS (Knowledge Management System) it affects the performance of employees, the results of the analysis can be expected to be an evaluation material that will have an impact on the company.
\end{abstract}

Keywordsi: Knowledge Management System, Knowledge Sharing, Knowledge Presentation Sharing, Knowledge

Abstrak - Knowledge Management System (KMS) untuk meningkatkan kualitas sumber daya manusia dalam suatu organisasi dengan meningkatkan komunikasi antar karyawan dan meningkatkan keterampilan dengan mentransfer pengetahuan. Knowledge Management System (KMS) adalah salah satu dari banyak cara untuk menumbuhkan budaya berbagi pengetahuan di antara individu dan organisasi. Dalam penelitian ini peneliti mencoba mengembangkan suatu model sistem manajemen pengetahuan yang sesuai dengan kondisi eksisting di Hotel XYZ berjalan dengan efektif, perlu dilakukan suatu kegiatan evaluasi dengan mengkaji proses pengelolaan pengetahuan yang dimiliki oleh setiap individu dapat ditransfer ke individu lain, individu melalui proses knowledge sharing dan knowledge presentation management dan melalui knowledge management yang efektif diharapkan dapat terpelihara dengan baik sehingga dapat memberikan manfaat bagi perusahaan. KMS (Knowledge
Management System) merupakan alat utama untuk mengimplementasikan proses-proses yang ada dalam knowledge management, perlu dilakukan analisis untuk mengetahui sejauh mana proses knowledge level management yang terdapat di Hotel XYZ pada tingkat kematangan KMS (Knowledge Management System) berpengaruh terhadap kinerja pegawai, hasil analisis tersebut diharapkan dapat menjadi bahan evaluasi yang akan berdampak pada perusahaan.

Keywordsi: Knowledge Knowledge Management System, Knowledge Sharing, Knowledge Presentation Sharing, Pengetahuan

\section{PENDAHULUAN}

Hotel XYZ merupakan sebuah hotel berbintang empat (4) yang terdapat di Kota Batam provinsi Kepulauan Riau dengan memiliki kamar sebanyak 254 kamar dan terdapat satu (1) Ballroom Cendana Meeting Point dengan mempunyai lima (5) departemen dengan karyawan berjumlah 103 Orang di perusahaan tersebut adapun department nya adalah Front Office, Housekeeping, Engineering, Accounting Finance \& HRD (Human Resource Department) maka diperusahaan tersebut banyak memiliki sumber daya manusia yang beraneka ragam, maka dari itu perusahaan tersebut memilki banyak pengetahuan yang harus dikelola dengan baik.

Kemajuan teknologi dan ilmu pengetahuan semakin meningkat dan tentunya itu merupakan tantangan baru pada perusahaan yang harus mengelola asset-aset knowledge yang terintegrasi dengan kolaborasi, sharing, inovasi, dan lain-lain untuk mendorong penciptaan knowledge management. Agar proses knowledge sharing yang sudah ada di Hotel XYZ dapat berjalan secara efektif, maka diperlukan suatu kegiatan evaluasi dengan meneliti bagaimana proses pengelolaan pengetahuan yang dimiliki oleh masing-masing individu dapat di transfer ke individu lainnya melalui proses knowledge sharing dan knowledge presentation management dan melalui pengelolaan pengetahuan yang efektif ini diharapkan dapat di maintenance dengan baik sehingga dapat memberikan manfaat bagi perusahaan. KMS (Knowledge Management System) menjadi sarana utama dalam pelaksanaan proses yang ada di dalam 
knowledge management itu sendiri, maka perlu dilakukan analisis untuk mencari tahu sejauh mana proses-proses level knowledge mangament yang terdapat di Hotel XYZ pada tingkat kematangan KMS (Knowledge Management System) nya mempengaruhi kinerja karyawan,

Hasil analisis yang ada dapat diharapkan dapat menjadi bahan evaluasi yang akan memberikan dampak bagi perusahaan nantinya. Banyaknya penyebab yang ditemukan dari masalah yang kemudian diperbaiki menggunakan framework COBIT 5 dalam bidang knowledge adalah masalah mengelola knowledge management SDM (Sumber Daya Manusia) yaitu sesuai penentuan tingkat kematangan (maturity level) pada KMS (Knowledge Management System) mengevaluasi melalui framework COBIT 5, Ditemukan masalah di Framework domain APO7 (Mnegatur SDM ) dan Framework domain EDM4 (memaksimalkan pengoptimal sumber daya manusia). Hasil temuan dan permasalahan tersebut perlu di review serta evaluasi untuk penataan kelola KMS (Knowledge Management System) di Hotel XYZ. Tata Kelola dalam evaluasi harus punya tujuan agar dapat mengetahui hasil dari nilai penentuan (maturity level) Evaluasi Tata Kelola dalam Hotel XYZ. Penulis disini membuat analisis nilai dari framework COBIT 5 untuk di review dalam Evaluasi tata kelola di Hotel XYZ sesuai proses domain dengan mengambil beberapa permasalahan yang ada. Hal inilah yang memilih bagimana mengevaluasi sampai dimana tingkat kematangan model KMS (Knowledge Management System) yang terdapat di Hotel XYZ dan memberikan rekomendasi berupa hasil untuk pencapaian ke level setingkatnya pada knowledge management.

\section{TINJAUAN PUSTAKA}

\section{A. Pengertian Proses}

Proses adalah serangkaian aktivitas yang ditujukan untuk mencapai beberapa hasil. Proses merupakan cara bagaimana sebuah pekerjaan menghasilkan nilai bagi pelanggan.

\section{B. Pengertian Model}

Model adalah menggambarkan perkembangan entitas dari waktu ke waktu, dengan entitas tersebut apapun yang menarik. Setiap entitas berkembang melalui level dari waktu ke waktu sampai mencapai tertinggi, di optimalkan, level. Menurut [10]. Pengembangan entitas tunggal disederhanakan dan dijelaskan dengan terbatas jumlah tingkat kematangan (biasanya empat hingga enam).

\section{Pengertian Knowledge Management}

Manajemen pengetahuan adalah pendekatan-pendekatan sistematik yang membantu tercipta dan mengalirnya informasi dan pengetahuan kepada orang-orang yang tepat pada saat yang tepat untuk menciptakan nilai tambah [8]. dan [3]. Evaluasi kegiatan KM (Knowledge Management) oleh praktisi KM "menerapkan pengetahuan" dinilai sebagai "penting" dan "sangat penting" oleh total 96 persen responden . Kegiatan penilaian membedakan antara penilaian untuk level 1 dengan level yang lebih tinggi.

D. Sejarah COBIT 5 Framework

Singkatan COBIT adalah Control Objective for Information and Related Technology ( COBIT ) yakni beberapa kumpulan dari sebuah dokumentasi untuk pengelolaan IT Governance yang baik dan berar serta dapat membantu tim audit IT atau pemakai (user) dan atasan manajemen, untuk mengelola gap antara kesenjangan, resiko bisnis perusahaan, kebutuhan dalam unit control dan permasalahan yang dihadapi [5] .

\section{E. Pengertian COBIT 5 Framework}

Cobit 5 Merupakan generasi terbaru dari panduan [4]. yang membahas mengenai tata Kelola dan manajemen IT. Cobit 5 dibuat berdasarkan pengalaman penggunaan COBIT selama lebih dari 15 tahun oleh banyak perusahaan dan pengguna dari bidang bisnis, komunitas IT, risiko, asuransi, dan keamanan dan pengukuran menurut [9].COBIT 5 menyediakan kerangka kerja komprehensif yang membantu perusahaan dalam mencapai tujuan mereka untuk tata kelola dan manajemen TI perusahaan. Dan [6]. COBIT 5 adalah edisi ke 5 dari kerangka kerja IT yang dibuat oleh ISACA untuk mengendalikan manajemen dan tata kelola teknologi informasi [4].

\section{METODELOGI PENELITIAN}

\section{A. Metode Pengembangan Sistem}

Disain penelitian berisi langkah-langkah yang digunakan dalam penelitian ini agar terstruktur dengan baik. Dengan sistematika ini proses penelitian dapat dipahami dan diikuti oleh pihak lain. Penelitian yang dilakukan untuk merancang sistem diperoleh dari pengamatan data-data yang ada. Adapun langkah-langkah yang dilakukan untuk mencapai tujuan dari peneltian ini adalah seperti dibawah ini. Penelitian Evaluasi Tata Kelola Manajemen sistem informasi menggunakan metode yaitu kualitatif. Untuk metode kuatitatif ini fokus pada meneliti kondisi dari objektif yang ada dalam kondisi Hotel XYZ. Instrumen yang dipakai adalah sumber daya manusia yaitu peneliti dengan sumber data yang ada kemudian pengambilan dalam teknik purposive dan snowball. Jenis temuan yang diusung adalah studi kasus. Studi kasus merupakan salah satu metode penelitian dengan fokus memahami individu secara integratif dan komprehensif sehingga tujuan utama memperoleh pemahaman dalam individu dan masalah yang dihadapi Hotel XYZ. Tujuan penelitian mengolah studi kasus adalah memperoleh pemecahan dari masalah sehingga bisa teratasi dan memperoleh perkembangan diri menjadi lebih baik lagi penelitian dengan mengelola analisis dan mengevaluasi tata kelola dan audit manajemen sistem informasi menggunakan Framework COBIT 5 di Hotel XYZ dengan fokus pada beberapa domain masalah yaitu domain APO7 tentang mengelola SDM, BAI04 tentang mengelola ketersediaan dan kapasitas SDM, DSS3 tentang mengelola pemecahan masalah, DSS6 tentang mengelola dan mengontrol hasil bisnis dan domain masalah MEA1 tentang monitoring, mengevaluasi, dan appraisal. Model penilaian yang akan dipakai adalah bagaimana mengetahui nilai tingkat kematangan (maturity) yang ada dalam tata kelola KMS (Knowledge Management System) pada Hotel XYZ berdasarkan model ISO atau IEC 15504. Berikut ini adalah gambaran dari metode penelitian. 


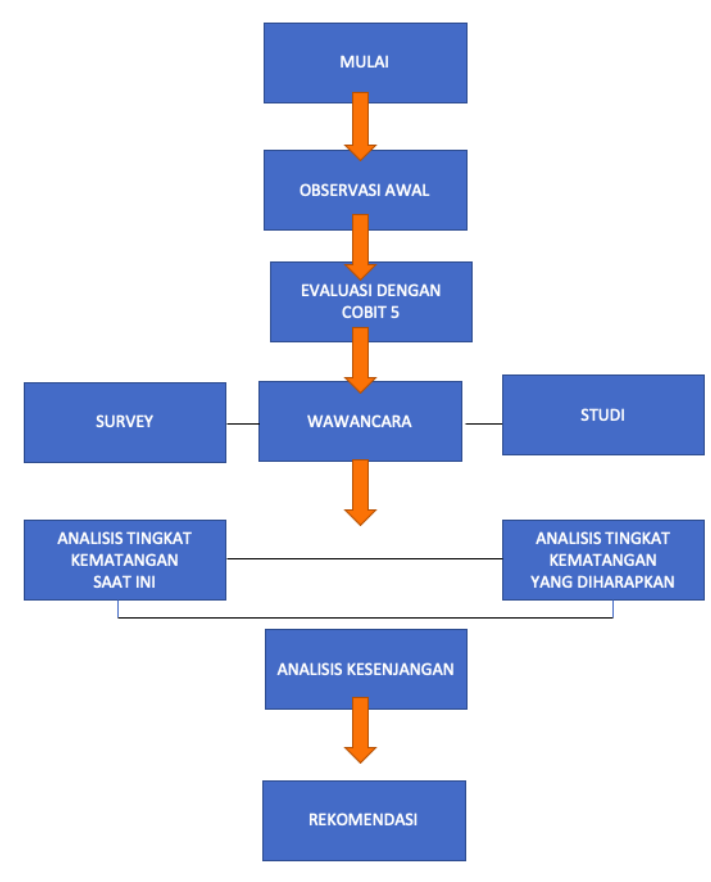

Gambar 1. Metode Penelitian

Role Model metode penelitian yang akan dilakukan selama penelitian berlangsung adalah sebagai berikut :

1. Tahap pertama dalam penelitian ini adalah dimana tim auditor IT melakukan observasi pertama, serta memahami masalah yang ada, selanjutnya dilanjutkan evaluasi sehingga diperoleh pemilihan domain masalah pada framework COBIT 5 yang berkaitan dengan masalah yang ada pada Hotel XYZ.

2. Tahap kedua dalam penelitian ini adalah pengumpulan data. Tahap ini setelah ditemukan masalah pada domain framework COBIT 5 menjadi draft kuisioner. Selanjutnya analisis survei menggunakan kuisioner yang telah disediakan sesuai dengan pertanyaan yang ditunjukan kepada tim manajemen kepentingan (stakeholder) dan juga selaku responden agar pertanyaan atau pernyataan kuisioner dapat dijawab dengan baik dan benar. Studi kasus lalu dokumentasi dan wawancara dilakukan agar dapat melihat sehingga mengevaluasi kondisi organisasi saat ini sebagai data penunjang hasil kuisioner.

3. Tahap ketiga dalam penelitian ini adalah teknikal analisis data yang dilakukan dengan tiga (3) cara agar bisa merumuskan fungsi dari rekomendasi perbaikan serta merta, analisis kematangan yang ada diperoleh dari hasil pengumpulan data yang di teliti. Analisis kematangan yang diharapkan dapat diperoleh dengan melakukan teknik wawancara kepada pimpinan hotel atau General Manager lainnya. Setelah itu dilakukan analisis kesenjangan diperoleh dengan membandingkan level GAP dan tingkat kematangan yang diharapkan dengan menilai pada acuan tingkat kematangan saat ini. hasil perbandingan ini harus diperkecil organisasi dalam kurun waktu tertentu dengan cara melaksanakan rekomendasi perbaikan masalah yang diberikan.KM (Knowledge Management) menyediakan keuntungan untuk pegawai individu, komunitas dari praktek, dan organisasinya sendiri [2].

\section{B. Metode Pengumpulan Data}

Metode pengumpulan data yang akan digunakan dalam penelitian ini adalah dengan melakukan studi kasus permasalahan kemudian melakukan wawancara kepada manajer TI dan manajer lainnya sesuai dengan kapasitasnya untuk memberikan penjelasan pada situasi tingkat kematangan (maturity level) pada KMS (Knowledge Management System) di Hotel XYZ saat sekarang ini. Kemudian di review hasil dari wawancara menjadi studli kasus.

\section{Studi Pustaka}

Metode pengumpulan data yang akan digunakan dalam penelitian ini adalah dengan melakukan studi kasus peermasalahan kemudian melakukan wawancara kepada manajer TI dan manajer lainnya sesuai dengan kapasitasnya untuk memberikan penjelasan pada situasi tingkat kematangan (maturity level) pada KMS (Knowledge Management System) di Hotel XYZ saat sekarang ini. Kemudian di review hasil dari wawancara menjadi studi kasus.

\section{Wawancara}

Pada metode ini, penulis akan mengumpulkan data dan informasi dengan cara melakukan wawancara secara langsung kepada pihak-pihak yang terkait dalam pengelolaan KMS (Knowledge Management System) dimana dalam hal ini narasumber adalah Department Head of Hotel XYZ dan manajemen lainnya selaku pengguna KMS ( Knowledge Management System) di Hotel XYZ.

\section{E. Pengertian Framework COBIT 5}

Framework COBIT versi 5 adalalah Framework COBIT dari ISACA yang menyediakan penjabaran bisnis secara lengkap dan end-to-end dari tata Evaluasi kelola teknologi informasi perusahaan dalam menggambarkan peranan utama dari sistem informasi dan teknologi dalam menciptakan nilai perusahaan. Framework COBIT 5 memiliki 37 control practices dan 209 control activities terkait domain proses tata kelola dan manajemen. Framework COBIT versi 5 ini membantu perusahaan menciptakan nilai yang optimal dengan cara menyeimbangkan antara keuntungan dan tingkat resiko penggunaan SDM (Sumber Daya Manusia).

\section{F. Tabel Pengukuran COBIT 5}

Pada metode ini, penulis akan memberikan table untuk proses pengukuran aktifitas framework COBITt 5 pada studi kasus Hotel XYZ yang telah di ambil sebuah domain dan prosesnya adalah sebagai berikut. 
TABEL 1. PROSES PENGUKURAN AKTIFITAS FRAMEWORK COBIT 5

\begin{tabular}{|c|c|c|c|}
\hline No & $\begin{array}{c}\text { Proses } \\
\text { IT }\end{array}$ & Aktifitas & Deskripsi Aktifitas \\
\hline \multirow{3}{*}{1} & \multirow{3}{*}{ EDM3 } & EDM03.01 & Mengevaluasi manajemen resiko \\
\hline & & EDM03.02 & Mengarahkan manajemen resiko \\
\hline & & EDM03.03 & Memantau manajemen resiko \\
\hline \multirow{3}{*}{2} & \multirow{3}{*}{ EDM4 } & EDM04.01 & Mengevaluasi sumber daya manajemen \\
\hline & & EDM04.02 & Mengarahkan sumber daya Manajemen \\
\hline & & EDM04.03 & Mengarahkan sumber daya Manajemen \\
\hline \multirow{5}{*}{3} & \multirow{5}{*}{ APO 7} & APO07.01 & $\begin{array}{l}\text { Memelihara susunan kepegawaian yang } \\
\text { baik }\end{array}$ \\
\hline & & APO07.02 & $\begin{array}{l}\text { Mengidentifikasi personil teknologi } \\
\text { informasi }\end{array}$ \\
\hline & & APO07.03 & $\begin{array}{l}\text { Memelihara kemampuan dan kompetensi } \\
\text { dari personil }\end{array}$ \\
\hline & & APO07.04 & Mengevaluasi kinerja pegawai \\
\hline & & APO07.05 & $\begin{array}{l}\text { Rencana dan alur penggunaan teknologi } \\
\text { informasi dan bisnis pada sumber daya } \\
\text { manusia }\end{array}$ \\
\hline \multirow{4}{*}{4} & \multirow{4}{*}{ BAI 4} & BAI04.01 & $\begin{array}{l}\text { Menilai ketersediaan, kinerja dan } \\
\text { kapasitas, dan menciptakan baseline. }\end{array}$ \\
\hline & & BAI04.02 & Menilai dampak bisnis. \\
\hline & & BAI04.03 & $\begin{array}{l}\text { Rencana untuk kebutuhan layanan baru } \\
\text { atau diubah. }\end{array}$ \\
\hline & & BAI04.04 & $\begin{array}{l}\text { Memantau dan ketersediaan ulasan dan } \\
\text { kapasitas. }\end{array}$ \\
\hline \multirow{5}{*}{5} & \multirow{5}{*}{ DSS 3} & DSS03.01 & $\begin{array}{l}\text { Mengidentifikasi dan mengklasifikasi } \\
\text { masalah }\end{array}$ \\
\hline & & DSS03.02 & Menyelidiki dan mendiagnosis masalah \\
\hline & & DSS03.03 & Membahas permasalahan terkait \\
\hline & & DSS03.04 & Menyelesaikan masalah \\
\hline & & DSS03.05 & Melakukan manajemen masalah proaktif \\
\hline \multirow{6}{*}{6} & \multirow{6}{*}{ DSS 6} & DSS06.01 & $\begin{array}{l}\text { Mensejajarkan kegiatan pengendalian } \\
\text { dalam proses bisnis dengan tujuan } \\
\text { perusahaan. }\end{array}$ \\
\hline & & DSS06.02 & Kontrol pengolahan informasi. \\
\hline & & DSS06.03 & $\begin{array}{l}\text { Mengelola peran, tanggung jawab, hak } \\
\text { akses dan tingkat kewenangan. }\end{array}$ \\
\hline & & DSS06.04 & Mengelola kesalahan dan pengecualian. \\
\hline & & DSS06.05 & $\begin{array}{l}\text { Memastikan alur informasi dan } \\
\text { akuntabilitas. }\end{array}$ \\
\hline & & DSS06.06 & Aset keamanan informasi \\
\hline \multirow{5}{*}{7} & \multirow{5}{*}{ MEA1 } & MEA01.01 & Menetapkan pendekatan monitoring. \\
\hline & & MEA01.02 & Mengatur kinerja dan kesesuaian target. \\
\hline & & MEA01.03 & $\begin{array}{l}\text { Mengumpulkan dan kinerja proses dan } \\
\text { kesesuaian data. }\end{array}$ \\
\hline & & MEA01.04 & Analisa dan melaporkan kinerja. \\
\hline & & MEA01.05 & $\begin{array}{l}\text { Memastikan pelaksanaan tindakan } \\
\text { perbaikan. }\end{array}$ \\
\hline
\end{tabular}

\section{G. Rumus Mencari Tingkat Kematangan}

Pada tahapan ini peneliti mengevaluasi penilaian tiap aktivitas berdasarkan jumlah hasil kuisioner. Kemudian peneliti mencari nilai rata-rata tiap domain maalah untuk mendapatkan niali tingkat kematangan saat ini (as-is). Penilaian tingkat kematangan setiap proses mengacu pada model ISO atau IEC 15504 dengan rumus tersebut :

$$
\text { Maturity }=\frac{\text { Total } \text { Nilai }}{\text { Iumlah soal }}
$$

\section{H. Pengukuran Framework COBIT 5}

ISO atau IEC 15504, atau dikenal juga dengan SPICE (Software Process Improvement and Capability determination) adalah suatu "kerangka kerja untuk penilaian proses" yang dikembangkan bersama oleh badan sertifikasi Internasional yang dikenal dengan ISO (International Organization for Standardization) dan IEC (International Electrotechnical Commission)[7]. ISO atau IEC 15504 awalnya diturunkan dari standar siklus hidup proses ISO 12207 dan digunakan sebagai dasar pembuatan CMMI. Berikut adalah gambar skala dari ISO atau IEC 15504 dbawah ini :

\section{ISO/IEC MeasurementScale}

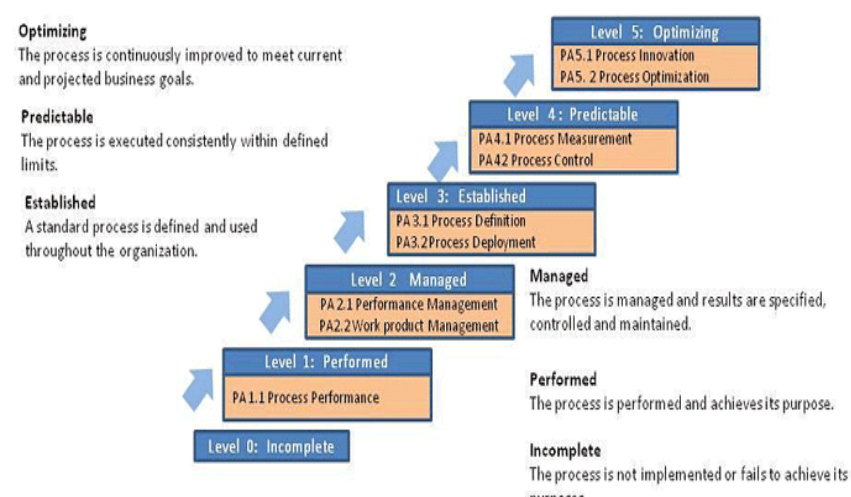
purposes.

Thisfigure is reproducedfromISO/EC IS504-2, with the permission of ISO/EECat www.150.0rg. copyright remains with ISO/IEC.

Gambar 2. Model Tingkat Kapabilitas ISO/IEC 15504

Dari gambaran di atas ISO atau IEC 15504 merupakan suatu kerangka kerja atau framework untuk melakukan penilaian proses. ISO atau IEC 15504 memiliki 4 kategori level antara lain sebagai berikut:

1. $\mathrm{N}$ (Not achieved atau tidak tercapai) adalah kategori ini memiliki sedikit bukti pencapaian atribut pada setiap proses dengan range berkisar $0-15 \%$.

2. $\mathrm{P}$ (Partially achieved atau tercapai sebagian) merupakan beberapa bukti mengenai pendekatan dan pencapaian atribut proses tercapai dengan range 15-50\%.

3. L (Largely achieved atau tercapai secara garis besar) merupakan pencapaian yang sangat signifikan sehingga memiliki bukti atas

4. F (Fully achieved atau tercapai penuh) artinya merupakan pembuktian dalam pendekatan yang sistematis dan komplit dengan pencapaian yang tinggi

\section{Pengukuran GAP Analysis}

Target atau harapan kematangan proses TI adalah kondisi ideal tingkat kematangan Activity yang diharapkan oleh manajemen perusahaan. Tingkat kematangan ini digunakan sebagai acuan dalam evaluasi tata kelola di perusahaan. Setelah 
mendapatkan Capability Level yang sedang berjalan (as-is) di perusahaan, kemudian dibandingkan ke Capability Level yang diharapkan (to-be) untuk dihasilkan Analisa Kesenjangan, dimana nilai kesenjangan didapatkan dari Nilai to-be dikurangi ke Nilai as-is. Data Capability Level saat ini (as-is) dan Capability Level yang diharapkan (to-be) dimasukkan kedalam Table Analisa Kesenjangan.

\section{J. Penentuan Rekomendasi}

Setelah mendapat proses-proses TI yang menjadi prioritas perbaikan maka akan menentukan kesimpulan terlebih dahulu menggunakan pendekatan deduktif yaitu penentuan kesimpulan dari fakta yang bersifat umum menjadi bersifat khusus atau spesifik. Penelitian ini dimulai dengan pemahaman mengenai Tata Kelola TI dan kerangka COBIT 5. Kemudian dari pemahaman tersebut, dilakukan penentuan tingkat kapabilitas dan akan ditentukan process practice dan rekomendasi aktivitas tiap-tiap proses untuk mendukung pencapaian tujuan proses. Penentuan process practice dan rekomendasi aktivitas mengacu pada panduan yang ada pada COBIT 5 Enabling Process.

\section{ANALISA DAN PEMBAHASAN}

Dalam bab ini akan membahas hasil penelitian evaluasi yang dilakukan terhadap apa yang diperoleh berdasarkan observasi dan evaluasi di perusahaan tersebut. Evaluasi data mencakup mengenai penilaian tingkat kematangan (maturity level) pada KMS (Knowledge Management System) di Hotel XYZ. Data yang didapat dari hasil wawancara diolah sesuai metode COBIT 5 Tahap-tahap analisis diawali dengan melakukan wawancara untuk mengetahui tingkat kematangan saat ini dan tingkat kematangan yang diharapkan kedepan sehingga akan diketahui berupa hasil rekomendasi sehingga dapat diperoleh menuju ke tingkat level kematangan diharapkan. Untuk mendapatkan hasil perhitungan tersebut, maka akan dilakukan analisis terhadap Strategi TI, Pengelolaan SDM dan Tata Kelola TI di perusahaan

\section{A. Analisis Kesenjangan}

Berikut ini adalah table dari analisis GAP

TABEL 2. ANALISIS GAP

\begin{tabular}{|l|l|l|l|l|}
\hline No & \multicolumn{1}{|c|}{ Proses Domain } & (as-is) & (to-be) & GAP) \\
\hline 1 & $\begin{array}{l}\text { APO 07 Mengelola sumber } \\
\text { daya manusia }\end{array}$ & 0.83 & 3 & $\begin{array}{l}(3-0.83)= \\
2.17\end{array}$ \\
\hline 2 & $\begin{array}{l}\text { BA14 Mengelola } \\
\text { Ketersedian dan Kapasitas }\end{array}$ & 1.5 & 3 & $(3-1.5)=1.5$ \\
\hline 3 & DSS3 Mengelola Masalah & 1.33 & 3 & $\begin{array}{l}(3-1.33)= \\
1.67\end{array}$ \\
\hline 4 & DSS6 Mengelola Masalah & 1.17 & 3 & $\begin{array}{l}(3-1.17)= \\
1.83\end{array}$ \\
\hline 5 & $\begin{array}{l}\text { MEA1 Monitor, evaluasi, } \\
\text { dan penilaian kinerja dan } \\
\text { kesesuaian }\end{array}$ & 0.83 & 3 & $\begin{array}{l}(3-0.83)= \\
2.17\end{array}$ \\
\hline & Rata-Rata & & $\mathbf{1 . 8 7}$ \\
\hline
\end{tabular}

Hasil dari perbedaan itu akan menghasilkan jarak atau
(GAP). Sehingga hasil analisis dari tingkat kesenjangan di Hotel XYZ maka tahap selanjutnya yaitu mengukur tingkat kesenjangan dari proses yang terpilih. Analisis kesenjangan (GAP analysis) dilakukan untuk mengetahui kesenjangan atau perbedaan yang terjadi antara kondisi saat ini dengan kondisi yang diharapkan. Analisis kesenjangan terhadap tingkat kapabilitas tata kelola TI di Hotel XYZ dilihat dari nilai kapabilitas proses COBIT 5 kondisi saat ini dan nilai kapabilitas target yang ingin dicapai. Berdasarkan wawancara dengan Division Head TI dan Manager lainnya serta General Manager didapatkan informasi bahwa target yang diinginkan adalah kapabilitas proses berada dilevel 3, yaitu Hotel XYZ mempunyai suatu unit kerja beserta struktur organisasi yang terkait dengan aktivitas teknologi informasi. Selain itu organisasi sudah mempunyai standar khusus (SOP) Standart Operation Procedure yang didefinisikan dari kebijakan terkait dengan aktivitas operasional dan pengembangan teknologi informasi
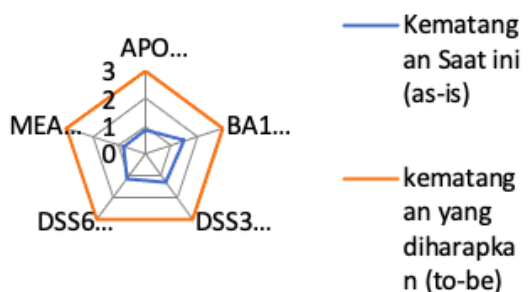

Gambar 3. Kesenjangan Masing-masing proses

Setelah mendapatkan Capability Level saat ini (as-is) dan Capability Level yang diharapkan (to-be) yang didapatkan berdasarkan hasil wawancara terhadap Head of IT Accounting and MIS Department diharapkan Divisi TI pada Hotel XYZ berada pada Capability Level 2 yang dapat dilihat pada Lampiran 1. Tahapan berikutnya adalah Gap Analysis terhadap Capability Level proses-proses COBIT 5 terpilih dan penentuan prioritas perbaikannya. Analisa kesenjangan ini adalah untuk mengetahui tingkat kesenjangan antara kondisi saat ini dengan kondisi yang diharapkan serta upaya yang harus dilakukan untuk meminimasi kesenjangan. Kondisi saat ini tercermin dalam hasil penilaian terhadap proses COBIT 5 saat ini dan kondisi yang diharapkan adalah target tingkat kapabilitas dari setiap proses. Dengan bantuan spider chart atau radar chart seperti yang terlihat pada gambar 3 .

Data kesenjangan antara tingkat kapabilitas current dan target digunakan untuk menentukan proses yang harus diutamakan untuk dilakukan perbaikan (Improvement). Menurut [4]. dalam document COBIT Self-Assessment Guide, rencana perbaikan awal dapat dilakukan pada bidang yang memiliki peran paling penting dalam pencapaian tujuan bisnis organisasi dan fokus pada bidang yang memiliki kesenjangan antara tingkat kapabilitas proses current dan target.

\section{B. Penentuan Keberhasilan GAP}

Setelah mendapatkan gap terhadap tata kelola yang berjalan 
pada Divisi TI Hotel XYZ, kemudian langkah berikutnya adalah menentukan prioritas perbaikan dengan menggunakan KPI (Key Performance Indicator). KPI (Key Performance Indicator) adalah indikator kunci yang digunakan untuk mengukur bagi pencapaian atau keberhasilan proses tata kelola pada Divisi TI sehingga dapat mencapai Capability Level 3. Pada Table 4.12 di bawah ini merupakan daftar KPI (Key Performance Indicator) dari proses-proses COBIT 5 yang terpilih.

\section{Rekomendasi}

Rekomendasi adalah sebuah saran yang akan diberikan penulis kepada management TI untuk keperluan perbaikan sistem informasi akademik kedepannya. Setelah mendapatkan hasil dari capability level, maka dapat dibuat table rekomendasi dan perbaikan untuk mencapai target (To be). Laporan ini diperoleh dari hasil analisis terhadap hasil perhitungan capability level dan analisis gap sebagai bentuk perancangan solusi untuk memberikan suatu usulan perbaikan. Usulan perbaikan yang disusun diarahkan agar perusahaan dapat mencapai tingkat kematangan sesuai dengan yang diharapkan.

\section{Rekomendasi APO07}

Rekomendasi adalah sebuah saran yang akan diberikan berikut ini adalah rekomendasi (1) Melakukan identifikasi dari setiap kebutuhan karyawan yang disesuaikan dengan kebutuhan perusahaan dalam kualitas maupun kuantitas ,(2) Membuat perencanaan yang baik dalam mengembangkan skill maupun soft-skill untuk meningkatkan kompetensi dari setiap karyawan. (3) Mengoptimalkan budaya knowledge-sharing dalam mengatasi hal-hal kritis sehingga mampu mengurangi ketergantungan individual.(4) Membuat report terhadap kompetensi yang dimiliki oleh setiap karyawan dan kemudian dilakukan analisis untuk dievaluasi kinerja dan performanya. (5) Membuat rencana-rencana perbaikan untuk setiap target yang belum dicapai oleh setiap karyawan. (6) Menyediakan penanggung jawab terkait pelaksanaan proses yang sudah ditentukan.(7) Mendefinisikan KPI Proses COBIT 5 yang relevan dengan manajeman SDM.(8) Membuat SOP untuk Process Definition dan Process Deployment terkait manajemen sumber daya manusia (SDM). Dan [1] Menurut teori KC, yang diperkenalkan oleh Nonaka dan Takeuchi (1995), pengetahuan diciptakan oleh model SECI yang mencakup empat mode, yaitu sosialisasi, eksternalisasi, kombinasi, dan internalisasi.

\section{E. Rekomendasi BA014}

Rekomendasi adalah sebuah saran yang akan diberikan berikut ini adalah rekomendasi (1) Merencanakan ketersediaan untuk mengantisipasi kebutuhan kapasitas kritis.(2) Membuat dokumentasi mengenai ketersediaan, performa dan kapasitas setiap sumberdaya.(3) Memantau kinerja dan ketersediaan telah memenuhi persyaratan yang telah ditetapkan dan permasalahan telah diidentifikasi dan rutin diselesaikan.(4) Menyediakan penanggung jawab, ditugaskan dan dikomunikasikan, dan memastikan komunikasi yang efektif dan juga kejelasan tugas dan tanggung jawabnya. (5) Menyediakan sumber daya dan informasi untuk melakukan proses yang sudah di identifikasi, disediakan, dialokasikan dan digunakan.(6) Menetapkan persyaratan untuk dokumentasi dan kontrol dari produk kerja yang telah didefinisikan dan mengulas hasil kerja untuk memenuhi ketersediaan.(7) Membuat SOP untuk memenuhi ketersediaan dan kapasitas. (8) Menyediakan sumber daya dan menetapkan aturan dan tanggung jawab supaya data dan informasi yang dikumpulkan dapat dianalisa sesuai dengan performa dari setiap proses (9) Mengevaluasi tingkat kinerja dalam semua tingkat pemprosesan (permintaan bisnis, kapasitas layanan dan kapasitas sumber daya) (10.)

Membuat dokumentasi terhadap skenario berdasarkan data yang dikumpulkan yang menggambarkan tingkat kapasitas potensial yang diperlukan untuk mencapai tujuan kinerja ketersediaan.

\section{F. Rekomendasi DSS3}

Rekomendasi adalah sebuah saran yang akan diberikan berikut ini adalah rekomendasi (1) Menentukan tingkat prioritas permasalahan dalam mengatasi masalah secara tepat waktu berdasarkan risiko bisnis dan definisi layanan.(2) Membuat sistem yang dapat mengetahui jalannya permasalahan (tricking system) yang dapat dipantau oleh pihak TI dan stakeholder terkait.(3)Melakukan identifikasi terhadap akar permasalahan, kemudian dokumentasikan dan menemukan solusi untuk pemecahan permasalaham tersebut

\section{G. Rekomendasi DSS6}

Rekomendasi adalah sebuah saran yang akan diberikan berikut ini adalah rekomendasi (1) Mempersiapkan prosedur pengelolaan bisnis proses tanpa menganggu operasional yang berjalan. (2) Mempersiapkan strategi perubahan (3) Mengevaluasi bisnis proses yang berjalan

\section{H. Rekomendasi MEA01}

Rekomendasi adalah sebuah saran yang akan diberikan berikut ini adalah rekomendasi (1) Membangun sebuah pendekatan mengenai aktivitas monitoring untuk mendefinisikan sasaran, ruang lingkup dan pengukuran kontribusi dari solusi dan layanan bisnis.(2)Melakukan monitoring terhadap proses kinerja dan evaluasi (3) Membuat sistem pengukuran kinerja.(4) Membuat sistem pengukuran kinerja.(5) Mengumpulkan hasil dari kinerja proses.(6) Menganalisis dan melaporkan hasil dari kinerja (7) Membuat sistem pengukuran kinerja.(8) Mengatur kinerja dan kesesuaian target.(9) Mengumpulkan hasil dari kinerja proses.

\section{KESIMPULAN}

Berdasarkan analisa gap yang didapat dengan level target yang ingin dicapai sesuai indicator Framework COBIT 5 pada APO07, dan hasil pengukuran capability level proses APO07, diperoleh kondisi level kapabilitas saat ini berada pada level 0 sedangkan yang diharapkan berada pada level 3, pada BAI04 dan hasil pengukuran capability level proses BA014, diperoleh kondisi level kapabilitas saat ini berada pada level 1 sedangkan yang diharapkan berada pada level 3, Berdasarkan analisa gap yang didapat dengan level target yang ingin dicapai pada DSS3 dan hasil pengukuran capability level proses DSS3, diperoleh kondisi level kapabilitas saat ini 
berada pada level 1 sedangkan yang diharapkan berada pada level 3, pada DSS6 dan hasil pengukuran capability level proses DSS6, diperoleh kondisi level kapabilitas saat ini berada pada level 1 sedangkan yang diharapkan berada pada level 3 , pada MEA01 dan hasil pengukuran capability level proses MEA01, diperoleh kondisi level kapabilitas saat ini berada pada level 0 sedangkan yang diharapkan berada pada level 3 , Jadi hasil yang diharapkan sampai saat ini berada pada level 3 yang artinya masih perlu di tingkatkan lagi menuju level 4.

\section{SARAN}

Setelah menarik kesimpulan dari hasil penelitian tersebut, maka dapat diajukan beberapa saran yang berkaitan dengan tingkat kematangan KMS (Knowledge Management System) yang ada di Hotel XYZ. Adapun saran yang diajukan disini adalah sebagai berikut (1) Tim IT dan pihak manajemen Hotel XYZ harus berfokus pada pencapaian Tingkat kematangan yang di inginkan yakni di Level 3.(2) Perusahaan beserta tim manajemen harus mempersiapkan pengontrolan pelaksana guna mencapai tingkat kematangan sesuai yang ditargetkan oleh karena itu proses di APO07, BA014, DSS3, dan MEA01 harus di tingkatkan kematangan yang semula level 1 dengan tingkat kematangan yang diinginkan adalah level 3.

\section{UCAPAN TERIMA KASIH}

Ucapan terima kasih kepada Universitas Internasional
Batam, Rektor, Dekan, Kaprodi , Dosen Sistem Informasi di Universitas Internasional Batam, begitu juga teman-teman yang saya cintai dan Penerbit yang telah menerbitkan jurnal Analisis Tingkat Kapabilitas Knowledge Management System Information Menggunakan Model Framework COBIT 5 (studi kasus Hotel XYZ)

\section{REFERENSI}

[1] Almulhim F Abdullah, 2017, The of Knowledge creation process on Organizational Performnce : Evidance from Saudi Banking Sector.

[2] Dalkir, Kimiz. (2011). Knowledge management in Theory and Practice. Massachusetts Insitute of Technology.

[3] Heisig: 2011, Unified Knowledge Management.

[4] ISACA. (2012). COBIT 5 Enabling Processes. USA: ISACA.

[5] ITGI. (2007). Framework Control Objectives Management Guidelines Maturity Models ISACA. (2012). COBIT 5 Enabling Processes. USA: ISACA.

[6] Jeffrey \& Joseph :2015, Suistainable IT Governance (SITG): Is Cobit An Adequate Model.

[7] Lanang Sadewa, 2013 Design Penerapan Activity Based Costing untuk menentukan harga pokok produksi pada Perusahaan Autobody Manufaktur dan Komponen Otomotif di CV Delima Mandiri.Fakultas Ekonomi Universitas Islam Negeri Syarif Hidayatullah Jakarta.

[8] Nawawi, Ismail. (2012). Manajemen Pengetahuan (Knowledge Management) Teori dan Aplikasi Dalam Mewujudkan Daya Saing Organisasi Bisnis dan Publik. Ghalia Indonesia. Bogor.

[9] Nugroho Heru: 2014, Conceptual Model of IT Governance for Higher Education Based on COBIT 5 Framework.

[10] Shekar Sivasubramanian: 2016, Process Model Knowledge Management. 